\title{
CONSERVAR LAS MEMORIAS COMO UN ACTO DE RESISTENCIA Y PERSISTENCIA $^{1}$
}

\author{
CONSERVAR AS MEMÓRIAS COMO UM ATO DE RESISTÊNCIA E PERSISTÊNCIA
}

\author{
Luis Carlos Toro Tamayo ${ }^{2}$ \\ Verónica Mejía Acevedo ${ }^{3}$ \\ María Cristina Paton ${ }^{4}$
}

RESUMEN: El presente texto indaga, desde una perspectiva crítica, en los retos que asumimos en la construcción de un sistema de colecciones al interior del Museo Casa de la Memoria de Medellín Colombia, y en las formas en las que se decide conservar este acervo documental como un acto de resistencia y persistencia de las memorias que hablan de Conflicto Armado en Colombia.

Palabras Clave: Derechos Humanos; archivos; repositorio digital; memorias subterráneas.

RESUMO: $O$ presente texto investiga, de uma perspectiva crítica, os desafios que assumimos na construção de um sistema de coleta no Museo Casa de la Memoria de Medellín - Colômbia, e as maneiras pelas quais se decide preservar esse patrimônio documental como um ato de resistência e persistência das lembranças que falam do conflito armado na Colômbia.

Palavras-chave: Direitos humanos; arquivos; repositório digital; memórias subterrâneas.

En memoria de Maria Cristina Paton, quien puso gran parte de su energía vital en este proyecto

\footnotetext{
${ }^{1}$ El presente texto hace parte de las reflexiones que plantea el proyecto "Puntos de encuentro entre las memorias inscritas y las memorias vivas", de la línea Memoria y Sociedad del Grupo de Investigación en Información, Conocimiento y Sociedad. Actualmente cuenta con el apoyo de la Organización Caminos de Esperanza Madres de La Candelaria, con la cofinanciación del Museo de Arte Moderno de Medellín (MAMM), la Escuela de Ciencias Sociales de la Universidad Pontificia Bolivariana y la Université de Lorraine; además recibe aportes del Centro de Investigaciones en Ciencias de la Información (CICINF) de la Escuela Interamericana de Bibliotecología de la Universidad de Antioquia - UdeA, Medellín - Colombia.

${ }^{2}$ Doctor en Langues et Littératures Romanes y doctor en Estudios Latinoamericanos de 1'Université Paris Ouest Nanterre La Défense y la Universidad de Chile, magíster en Lingüística e historiador de la Universidad de Antioquia. Profesor de la EIB, Universidad de Antioquia - UdeA.

${ }^{3}$ Magíster en Historia del Arte de la Universidad de Antioquia y artista plástica de la Universidad Nacional de Colombia. Hizo parte del equipo de curaduría del Museo Casa de la Memoria (Medellín - Colombia) entre 2015 y 2019.

${ }^{4}$ Doctora en Historia de la Universidad Torcuato Di Tella en Argentina, magíster en Estudios Latinoamericanos de la Universidad Andina Simón Bolívar e historiadora de la Universidad Nacional de Colombia. Fue líder Centro de Recursos para la Activación de la Memoria "María Teresa Uribe de Hincapié" del Museo Casa de la Memoria (Medellín - Colombia) entre 2015 y 2019.
} 


\section{Presentación}

A partir del análisis de los documentos, contenidos audiovisuales y materiales producidos por el Museo Casa de la Memoria de Medellín, desde su creación en 2006, hasta la actualidad, un equipo de trabajo interdisciplinario de museógrafos, historiadores, archivistas y artistas plásticos, entre otros, decidimos iniciar un ejercicio de organización documental que suscitó una serie de interrogantes sobre el sentido y la pertinencia de construir una colección que conservara las memorias de las luchas sociales y de los grupos que trabajan en defensa de sus derechos en un contexto social, cultural y político como el que vive Colombia, país en el que dichas violencias continúan presentes.

Estas memorias subterráneas (POLLAK, 2006, p. 18), silenciadas hasta ahora por estructuras hegemónicas de poder que no ven más allá de la supremacía del código escrito (Rama, 1984), nos brindan la posibilidad de comprender otra dimensión de los archivos y hacen que cobren valor documental un sinnúmero de soportes informativos que han sido desestimados desde las disciplinas y las instituciones facultadas para hacerlo. De este modo, en dicho proyecto insistimos en la necesidad de salvaguardar aquellas memorias alternativas señaladas por Taylor (2016) como: memorias inscritas (documentos, grabaciones, fotografías, etc.), así como las memorias vivas (talleres, eventos, exposiciones, etc.), que se producen en el devenir continuo de la institución, y que mediante proyectos de investigación, exposiciones museográficas, producciones bibliográficas, experiencias pedagógicas, entre otras, visibilizan procesos de construcción de nuevas memorias que nos hablan sobre la defensa de los derechos de las víctimas, la resolución de conflictos, la paz y los procesos de reconciliación que se producen como un modo de resistir y persistir en la conservación de las memorias que hablan sobre el Conflicto Armado en Colombia.

Dicho proyecto se hizo en el marco de una alianza interinstitucional entre la Escuela Interamericana de Bibliotecología de la Universidad de Antioquia y el Museo Casa de la Memoria, para concretar, de manera participativa y colegiada, el diseño y estructuración de un sistema de información documental que integrará las colecciones museológicas, archivísticas y bibliográficas del museo, siguiendo los protocolos que definen las ciencias de la información para la organización documental y bibliográfica, y respondiendo a las necesidades de una institución encargada de visibilizar dichas memorias como parte de sus ejes misionales. A continuación presentaremos algunas definiciones museológicas y documentales que dicha institución asumió para conservar estas memorias, y cómo los expertos en ciencias de la información procedimos con la implementación de un protocolo de organización documental que dio como resultado la implementación y puesta en marcha del Repositorio Digital del Museo Casa de la Memoria de Medellín - Colombia: http://colecciones.museocasadelamemoria.gov.co/repositorio/

\section{Crear un archivo vivo}

Conscientes de la necesidad de consolidar una colección que supliera las necesidades de una comunidad creciente de usuarios conformada por investigadores, familiares de víctimas y público general, surgió en 2018 la idea de construir un proyecto de organización de las colecciones del Museo Casa de la Memoria de Medellín, que fuera de libre acceso y en formato 
digital, y cuyo propósito consistiera en reunir el material producido en el marco de los proyectos investigativos, pedagógicos, sociales, culturales y expositivos desarrollados por la institución. Para lograrlo, fue necesario hacer un diagnóstico inicial del tipo de información que se conserva, entre las que se destacan información museológica, archivística y bibliográfica, y definir lo que se quería guardar, y lo que por obligación o falta de protocolos de autorización y uso de información se debía descartar. Dichas acciones obligaron a definir una serie de políticas que fueran aplicables a la información que se tenía y que sirvieran en el futuro para aplicarlas incluso a materiales que aún no habían sido tenidos en cuenta y que poseían gran valor documental.

Los límites que supone la catalogación documental han impedido la inserción de otro tipo de registros alternativos que hacen parte de la información que producen las instituciones, sobre todo aquellas en las que cada huella, cada registro del pasado, podría constituir material probatorio frente a la justicia. Nos referimos específicamente a organizaciones de derechos humanos o instituciones como el Museo Casa de la Memoria de Medellín, Colombia, que conserva en sus acervos y colecciones un amplio número de piezas y de registros que son producto de sus actividades propias, pero también de sus convocatorias de activación de memorias, sus exposiciones, talleres y laboratorios, y por supuesto, las investigaciones, tanto internas como externas, que involucran comunidades vulnerables que han vivido de manera directa o indirecta los flagelos de la guerra.

Como señala el Consejo Internacional de Museos (ICOM, 2017), las colecciones de los museos deben ser entendidas en su calidad de testimonios primordiales, razón por la que se tiene la obligación de facilitar, en la medida de lo posible, el libre acceso a la información, máxime si hablamos de un museo que fue creado con la misión de contribuir a la transformación de las lógicas de la guerra y a preservar una memoria que nos permita comprender cómo se dieron los hechos, cuáles fueron las acciones emprendidas por la sociedad civil en la búsqueda de los desparecidos, qué respuesta obtuvieron de los sectores oficiales y cómo procurar el acceso a la verdad, la reparación y la no repetición de los mismos (CONCEJO DE MEDELLÍN, 2015).

En tal sentido, para iniciar un proceso de organización de las colecciones del Museo Casa de la Memoria debíamos partir de una discusión inicial que permitiera llegar a consensos como el de conservar el orden original de producción de la información, y por consiguiente la funcionalidad que esta debía tener a la hora de ser dispuesta en un sistema de consulta abierto al servicio de la sociedad. Lógicamente esto también implicó hacer una evaluación del tipo de información con que se contaba, la cual proviene, en gran medida, del trabajo con comunidades, organizaciones y públicos de diversas naturalezas que han participado en actividades pedagógicas y sociales, y que por ser población vulnerable y afectada directamente por el conflicto armado dicha información debía ser tratada de manera especial.

El acervo documental del que hablamos posee en su mayoría información digital y además otro tipo de formatos de naturaleza híbrida que fueron o son parte de las exposiciones central y temporales del museo, así como materiales impresos entre los que se destacan libros y fotografías, entre otros. La necesidad de organizar toda la información del museo en una gran colección generó otro tipo de acciones como la creación de un plan de gestión documental en 2018, el cual definió, entre otras, la manera en la que se dispondría la información mediante la implementación de un sistema de Tablas de Retención Documental, proceso que se construyó de forma paralela con el proyecto de colecciones. 
Para la compilación de la información tomamos como base las copias de respaldo que realiza el área de sistemas del museo. La información faltante tuvo que ser extraída directamente de los computadores del personal del museo o de discos de almacenamiento externo que los mismos funcionarios conservan para salvaguardar la información. Seguidamente, y una vez reunida la información requerida, se inició con la etapa de depuración a través de un proceso de diagnóstico en el que se separó la información administrativa de la misional y se depuró el material repetido o dañado. Durante este proceso, que derivó en la creación de un acervo de los contenidos producidos desde 2011 hasta 2018, encontramos varias dificultades como duplicidad en documentos, falta de información de contexto de la información, problemas con la marcación y catalogación de los archivos, entre muchas otras, que conllevaron a la planeación de acciones de mejoramiento en lo relacionado con la organización de los archivos.

Paralelo al trabajo de depuración de la información, un equipo de personas se encargó de la revisión de los procesos y las dinámicas del trabajo al interior de la institución, con el propósito de entender el origen de la documentación producida y, desde ahí, esbozar las líneas de la futura colección del Museo Casa de la Memoria. La forma de guardar y organizar la información derivó en necesidades como la articulación de los equipos de trabajo y la redefinición de los ciclos que debía seguir la información, haciendo especial énfasis en el ciclo de construcción de las exposiciones, proceso en el que participan todas las áreas, en comparación con otros proyectos como los educativos y de investigación.

La curaduría en el museo no es una labor que recae en una sola persona, es una práctica que recoge los trabajos y avances de las áreas en relación con la investigación planteada, y se nutre de los conocimientos especializados de las personas que conforman los equipos en un escenario participativo, nombrado Comité de Creación y Producción de las Exposiciones (Creaprod). El museo reconoce que cada proyecto curatorial es diferente a los anteriores, no solo por las temáticas planteadas, sino porque los objetivos, alcances y metodologías son definidos de forma diferente para cada uno, dependiendo del tipo de situación que se quiera representar y las narrativas y puntos de vista que se quieran puntualizar para una mejor visibilización y socialización de las memorias.

En la redefinición de la forma de organizar la información el museo buscó una asesoría externa que permitiera, a través de la realización de una serie de talleres, identificar la propia percepción del equipo de trabajo sobre el funcionamiento orgánico de las áreas en este proceso $^{5}$. Así, los integrantes de los equipos de curaduría y museografía, investigación, pedagogía, comunicaciones, promoción del lazo social y planeación, establecieron un dialogo sobre los procesos de creación de las exposiciones y lograron definir el flujo de los procesos para identificar, por ejemplo, quiénes participan, cuándo y cuáles eran los productos que resultan en cada momento, entre otras. Esto con el objetivo de construir conjuntamente una estructura que permitirá organizar cada proceso en carpetas, las cuales unidas conformarían el archivo de la institución.

\footnotetext{
${ }^{5}$ La asesora para este proceso fue Melissa Aguilar, curadora e investigadora independiente con amplia trayectoria en curaduría y producción museográfica.
} 


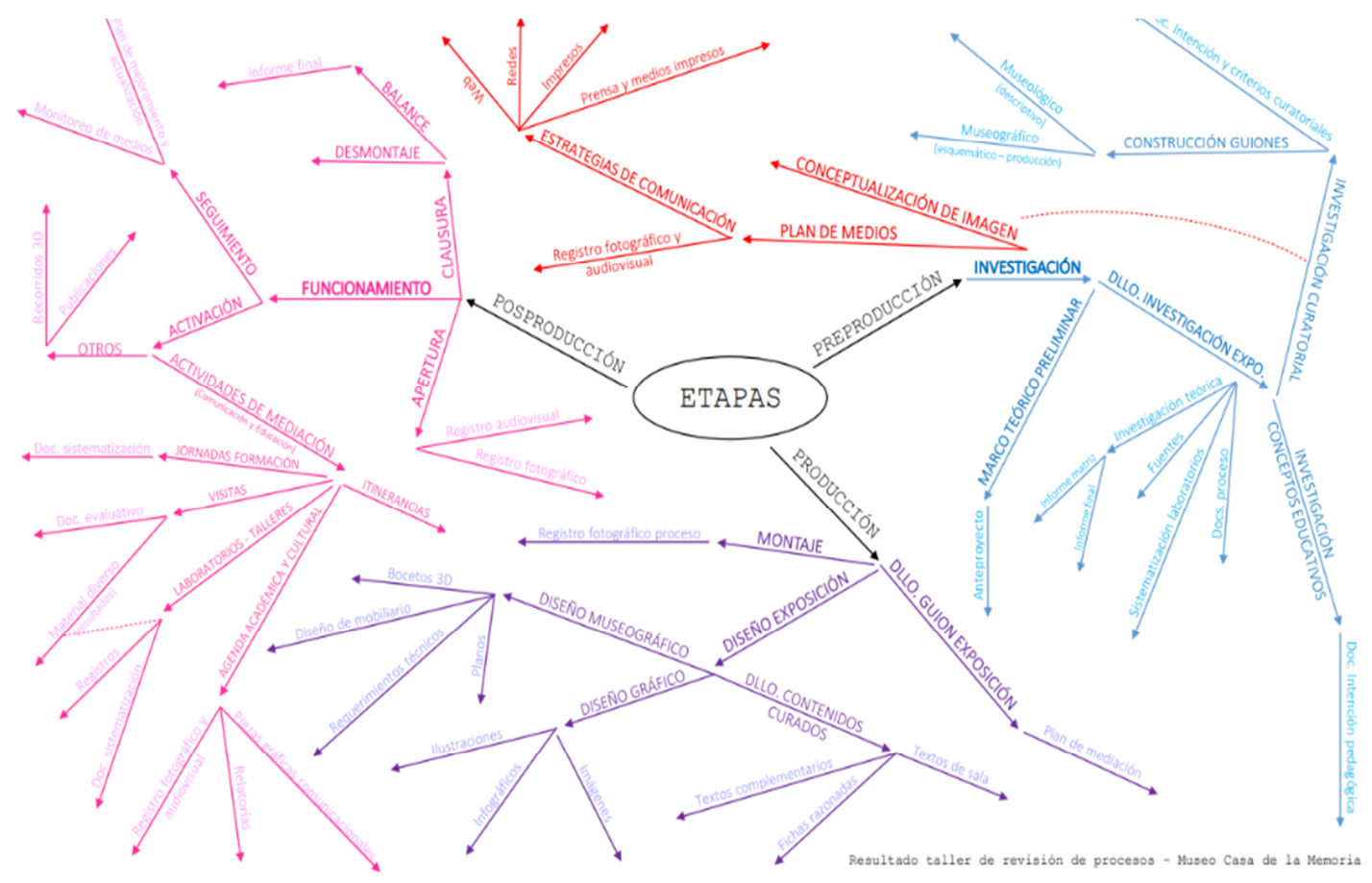

Imagen 1: esquema de procesos y productos expositivos del Museo Casa de la Memoria

El esquema realizado permitió visualizar los procedimientos y productos, así como las categorías en las cuales se guarda la información de cada exposición y la articulación entre los diferentes equipos que participan en el proceso. Permitió también reafirmar que cada proyecto tiene sus flujos particulares. Este tipo de esquema no jerárquico, que puede extenderse desde cualquiera de sus raíces, resultó idóneo para representar la organicidad de los proyectos expositivos y sus posibilidades de proponer nuevos vínculos en cualquiera de las etapas de organización del sistema de colecciones.

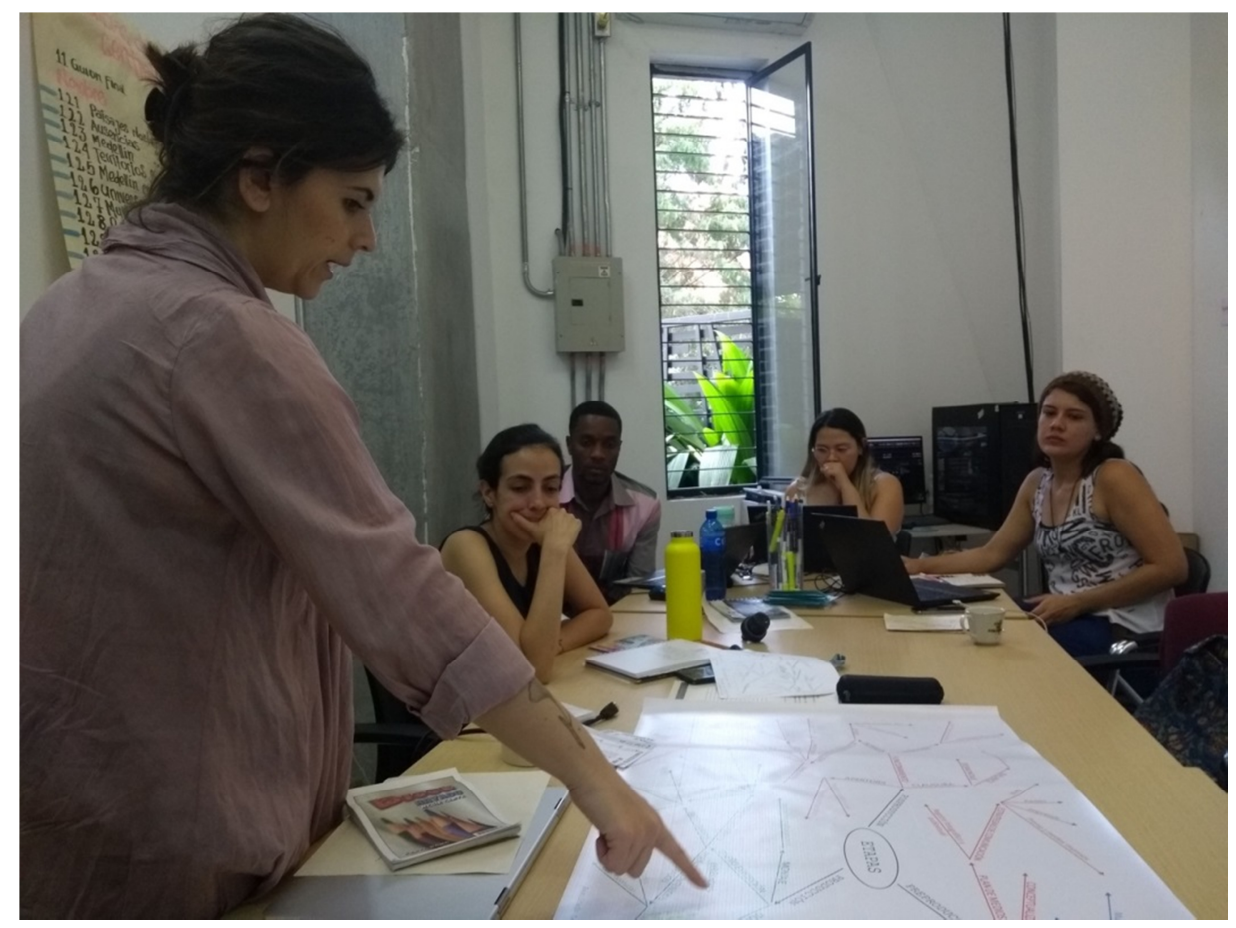

Imagen 2: sesión de trabajo de análisis de la información recogida durante los talleres que indagaron sobre los procesos de creación de las exposiciones. 
La preparación, clasificación, indexación, almacenamiento y recuperación de la información requieren de una serie de acciones que pasan por la evaluación, usando medidas cualitativas y cuantitativas (FUENTES, 1999, p. 161), en las que se consideran los documentos desde sus funciones misionales hasta la proyección de las necesidades de los potenciales usuarios del sistema. La revisión de los procesos de construcción de las exposiciones sirvió en gran medida para elaborar una propuesta de modelo de clasificación de la información del museo, dando especial énfasis a la documentación relacionada con los proyectos expositivos. Nuestra tarea se centró en la organización y análisis del material con valor artístico, histórico, testimonial y pedagógico del museo, el desarrollo de las políticas de la colección y la organización de una primera muestra documental que sería subida al repositorio digital y que debía dar cuenta de las complejidades que entrañan los ejercicios de memoria en un intento por comprender los impactos de la violencia que hemos sufrido en nuestra sociedad.

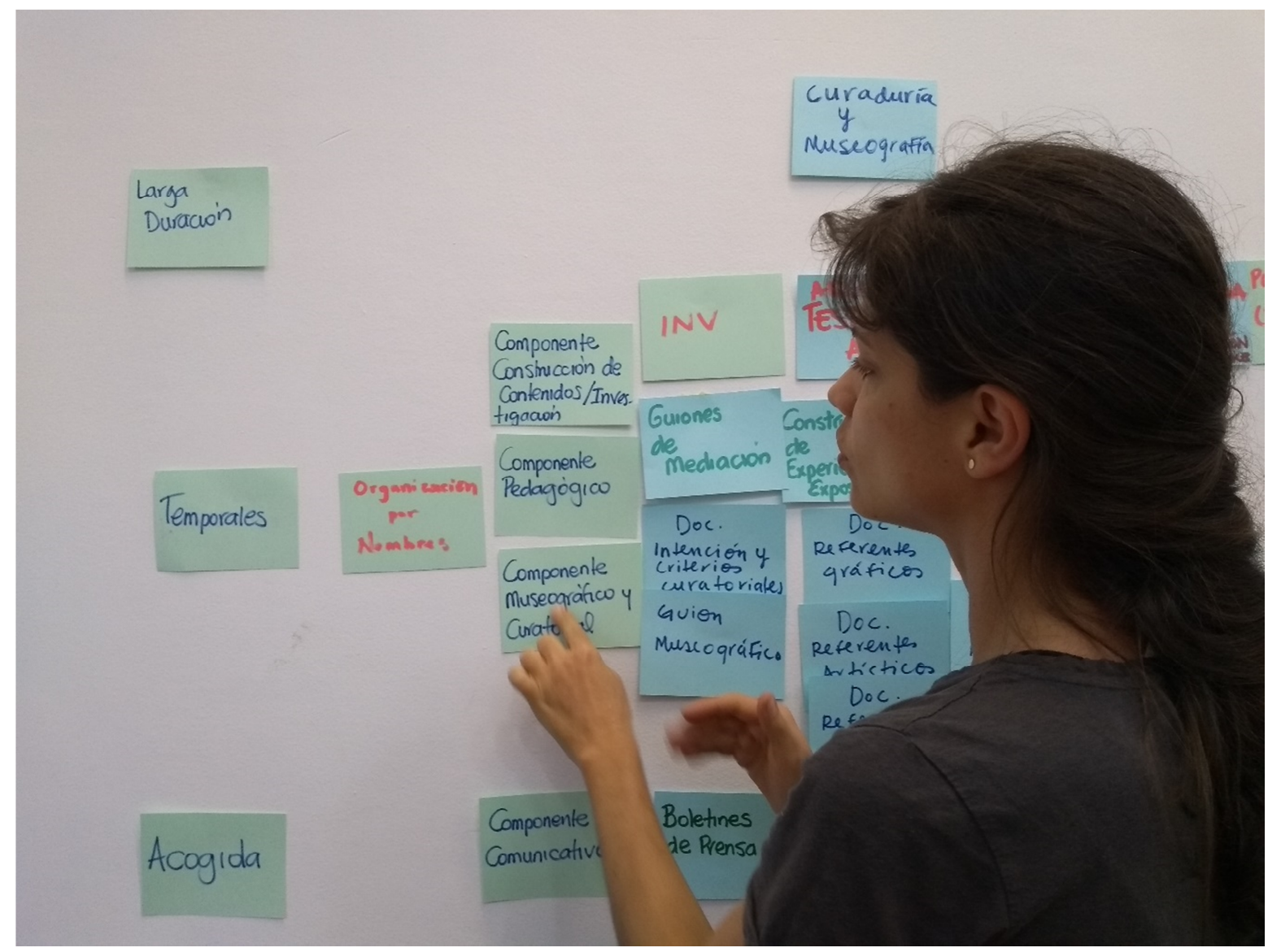

Imagen 3: construcción de estructura por parte del equipo del Museo Casa de la Memoria

Ejercicios de memoria entendidos en un doble sentido: la memoria ligada a la intimidad, a la privacidad y a los sentimientos; y la memoria como práctica colectiva que se materializa en las conmemoraciones, lugares y experiencias de construcción de memorias que realiza la institución. Con esta articulación buscábamos proyectar estrategias flexibles y creativas que nos permitieran comprender memorias en tránsito, entre lo privado y lo público, lo hegemónico y lo subterráneo. 
Para el equipo de trabajo de este proyecto es indispensable que la estructura del sistema sea comprendida por los potenciales usuarios, siempre pensando que las memorias que visibiliza el Museo hacen parte de las memorias de la ciudad, razón por la cual es necesario garantizar que su estructura sea orgánica, simple, desligada de los esquemas predefinidos por instituciones hegemónicas para que refleje la verdadera esencia de un proyecto que busca ser un lugar para la sociedad, una casa para todos.

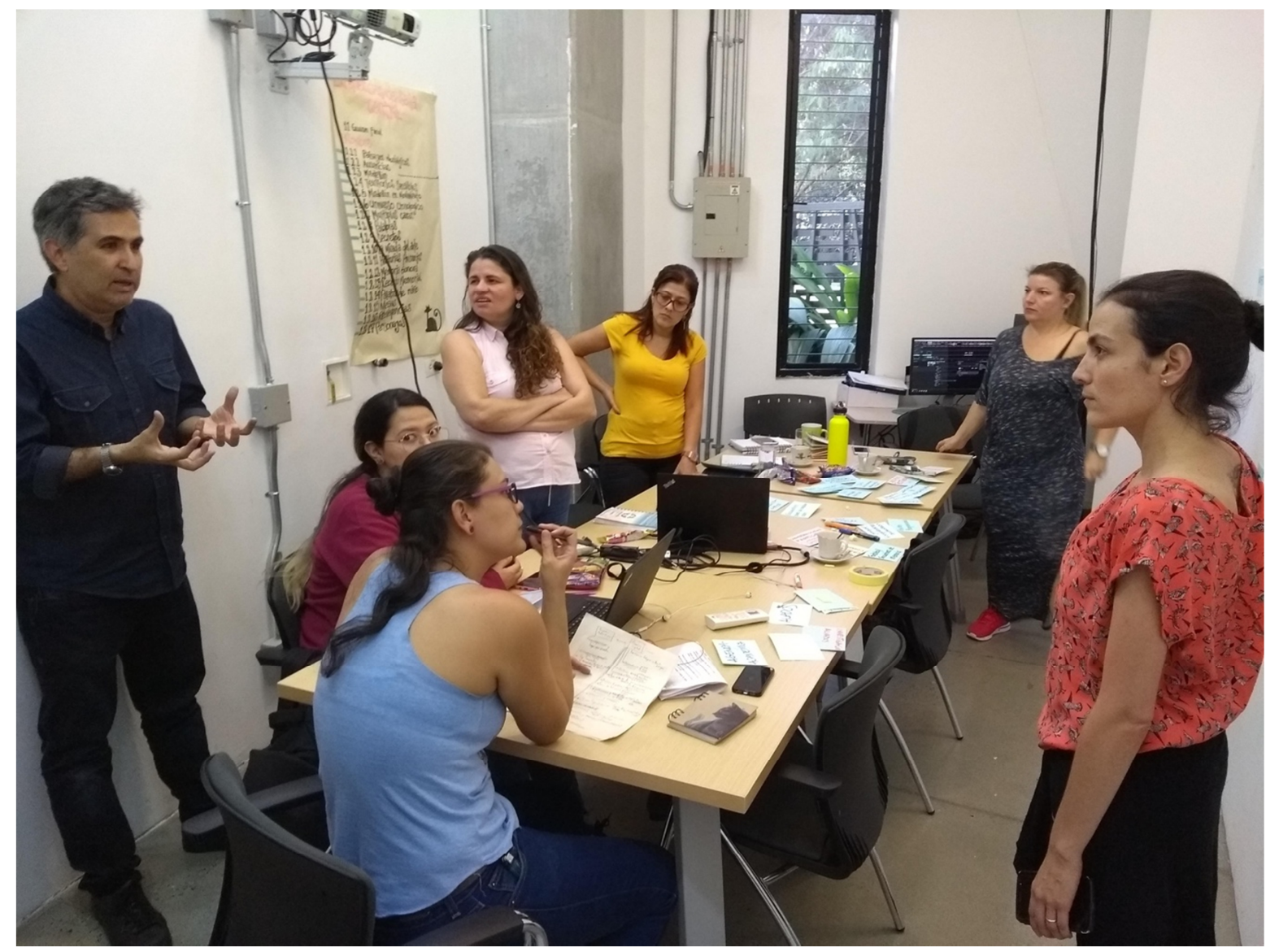

Imagen 4: construcción de estructura por parte de los equipos del Museo Casa de la Memoria y la Escuela de Bibliotecología de la Universidad de Antioquia.

De este modo, la estructura resultante que se llevó al repositorio digital obedeció a tres conceptos rectores de la institución, acordes con su denominación y el sentido de cada uno de las palabras que la definen:

- Museo: Unidad documental que reúne toda la documentación relacionada con las exposiciones, en cada una de sus fases, desde la creación, hasta el montaje y la exhibición.

- Casa: Unidad documental que reúne las memorias de los proyectos educativos y el relacionamiento con las comunidades reflejado en talleres, eventos, itinerancias, entre muchas otras actividades.

- Memoria: Unidad documental que compila el archivo documental, banco de testimonios y piezas de memoria de todos los proyectos del museo y que se concentra en el CRAM (Centro de Recursos de Activación de las Memorias). 

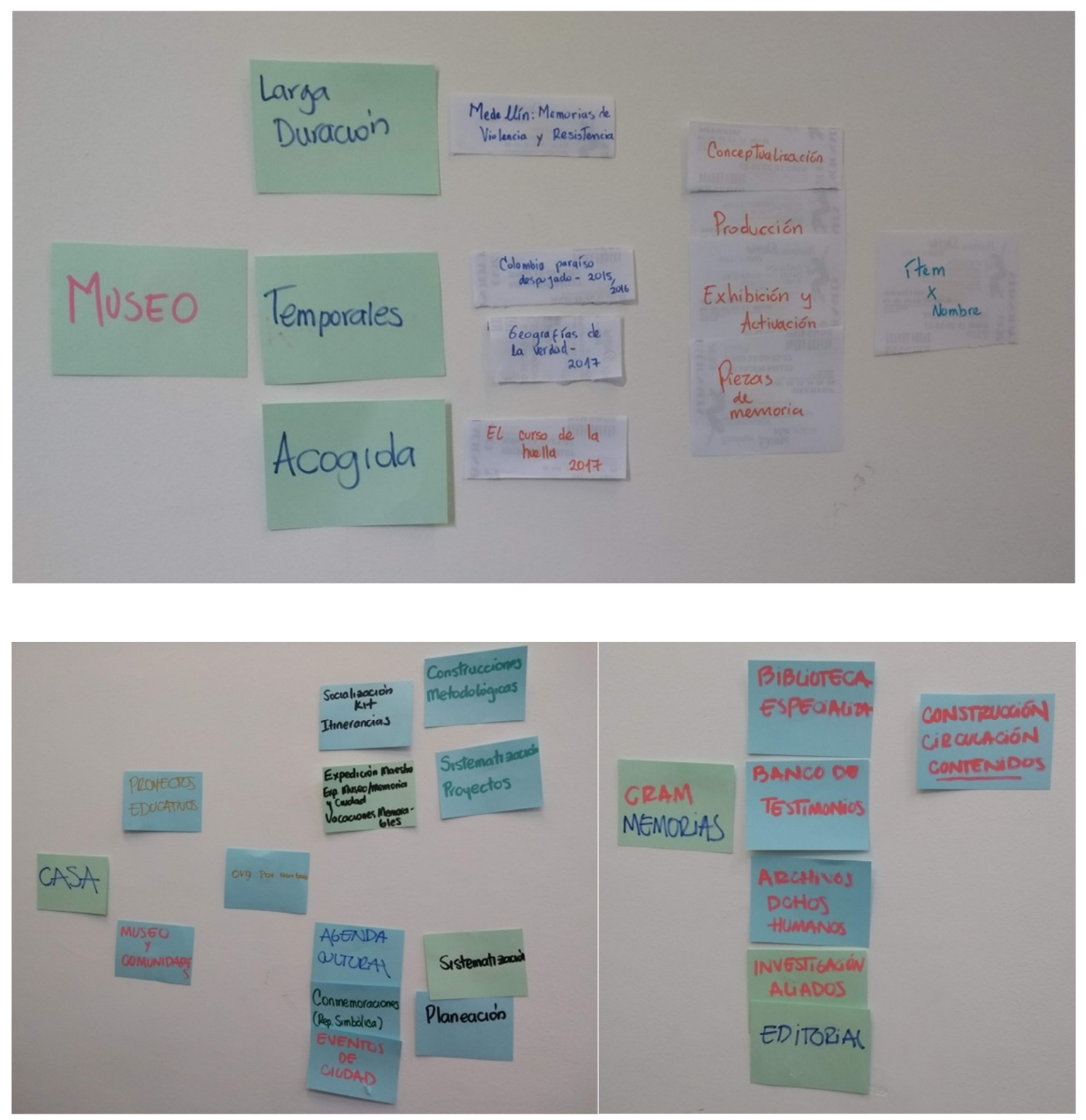

Imágenes 5, 6, 7. resultados iniciales de las sesiones de construcción de la estructura del repositorio.

De acuerdo con esta nueva estructura, toda la información audiovisual, los documentos y los objetos registrados en el sistema, así como las acciones y experiencias reunidas, serán parte de las memorias inscritas y las memorias vivas que posee el Museo Casa de la Memoria de Medellín en temas como el conflicto armado, las violencias políticas y sociales, la construcción de paz, entre otras. El valor documental de este tipo de soportes se da en virtud de los contextos en los que se producen estas memorias y el tipo de lectura y disposición que se haga de cada uno de los registros obtenidos en el ejercicio de recordar. No obstante, los retos que conlleva organizar y preservar estas memorias superan las lógicas tenidas en cuenta hasta ahora y nos hace reflexionar sobre otros factores de naturaleza jurídica, en la que la vulneración de los derechos humanos está en juego. 


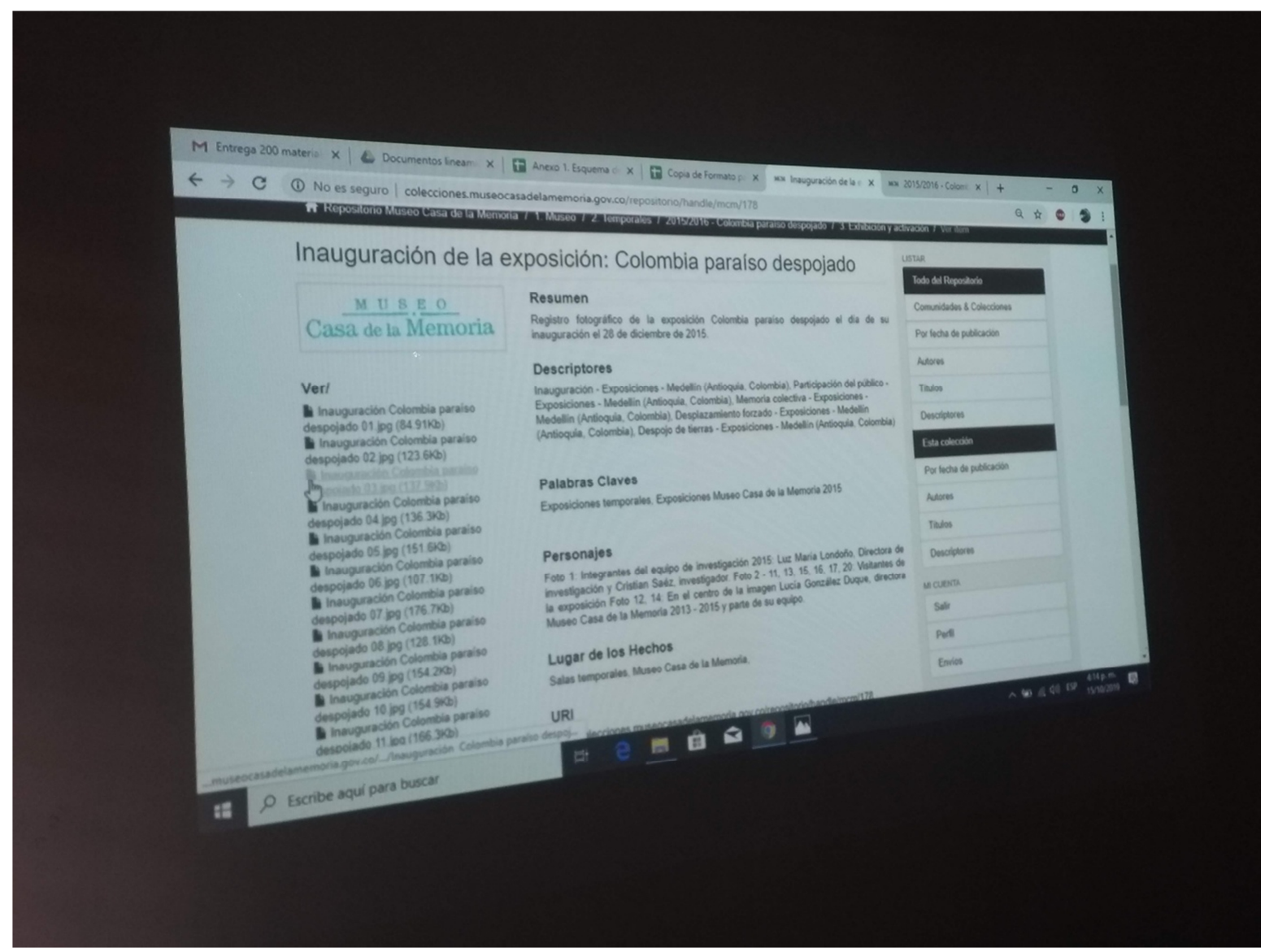

Imagen 8: visualización del repositorio en funcionamiento.

\section{Retos en la conservación de las memorias}

Por paradójico que parezca, buena parte de la información que conserva el Museo, o ha sido donada por agentes de memoria externos a la institución, fue construida a partir de ejercicios de acción participativa realizados con comunidades vulnerables, en los que se omitieron protocolos predefinidos recientemente por la legislación, lo que hoy impide que esa información sea dispuesta en el repositorio por carecer de consentimientos que permitan su utilización. Adicionalmente, debemos considerar que el Museo cuenta con información importante de sus procesos internos, tanto museológicos como pedagógicos y de investigación, entre otros, que, si bien pueden ser conservados para documentar las prácticas que realiza en cumplimiento de sus funciones misionales, no necesariamente deben ser de libre acceso en el repositorio. Con este tipo de clasificación se pretende salvaguardar los procesos que conllevan, por ejemplo, la investigación, planeación y realización de una exposición, después de pasar por todo el ciclo curatorial, pero privilegiando solo las piezas finales que se pueden asumir como productos terminados.

El descarte en la selección de documentos es siempre una ardua labor, máxime si hablamos de materiales digitales de los que se conservan cientos de versiones de un mismo documento. Según Huyssen (2002), el uso de la tecnología en la preservación de la memoria nos plantea el reto de seleccionar los pasados utilizables frente a los pasados descartables que 
atentan contra la comprensión de los procesos de construcción de memorias. Por su parte, Halbwachs (2006), plantea que la memoria colectiva solo se puede aprehender por medio de una metodología que trascienda los límites de las disciplinas. Bajo estos postulados, el diseño y estructuración de un sistema de información que permita la integración de las colecciones documentales del Museo Casa de la Memoria debe tener en cuenta todas las formas de producción, las lógicas de pensamiento, las maneras en las que se construyen los procesos creativos que conlleva, por ejemplo el diseño de un guion curatorial; o una estrategia pedagógica; o una investigación que contenga narrativas sobre situaciones límites que vulneren los derechos humanos.

Esto sin duda es un proceso de negociación, de selección pactada por los diferentes agentes de la memoria que intervienen en el proceso de conciliación entre las diferentes memorias individuales que le dan forma al pasado. Parafraseando a Pollak (2006, p. 18): existen memorias subterráneas que descubren situaciones que reflejan la compleja trama de la que está hecha la memoria colectiva. Son memorias minoritarias que se oponen a la memoria oficial, y que por su naturaleza contradictoria de los discursos dominantes posicionados a partir de mecanismos de control estatal no son visibles o, peor aún, son ignorados en las esferas de difusión de las memorias.

Somos enfáticos en señalar que muchas de estas memorias están siendo suprimidas, amenazadas, alterados sus significados a partir de acciones de destrucción sistemática de documentos y de monumentos. En tal sentido, el reto de sacar adelante un repositorio en el que se conserven estas memorias, no con el ánimo de acumular, sino de construir un sistema de información que sirva a la sociedad como insumo en sus reflexiones sobre el pasado y aporten significativamente en la construcción de un futuro ejemplar, nos permite vislumbrar las múltiples posibilidades que se abren para la investigación, la defensa de los derechos y la búsqueda de la verdad.

Así mismo, hacemos hincapié en la salvaguarda de un pasado ejemplar que contrasta con una memoria literal portadora de riesgos, la cual se presenta como un legado potencialmente liberador que busca, más que generalizar, establecer comparaciones para hacer evidentes las diferencias y las semejanzas en la búsqueda de la verdad. Dicha relación de convivencia nos permitirá avanzar, no olvidar, a la vez que proponer nuevas reflexiones sobre el pasado para que no se repitan los hechos atroces que han marcado la historia de nuestras sociedades (TODOROV, 1997, pp. 41-45).

El buen uso de las memorias que se le dará a este nuevo sistema de información pretende hacer una selección de la información, como rasgo inherente de la memoria y el olvido, con el ánimo de preservar aquellas piezas que muestren cómo ha sido la labor del museo durante todos estos años; cuál es su legado a las nuevas generaciones; qué propuestas se gestaron en sus diferentes administraciones; cuáles fueron los lenguajes utilizados y los insumos que nutrieron las exposiciones que se exhiben en sus diferentes salas; cuál es la ruta que siguen las investigaciones y cómo estas son llevadas a la comunidad mediante acciones de formación y propuestas pedagógicas de enseñanza y visibilización de las memorias.

Los procesos de construcción de un sistema de información son tan complejos como la manera en la que se produce la información. Las redes que se construyen en un espacio como el Museo Casa de la Memoria serán visibles en este repositorio con el propósito de hacer evidentes los diferentes procesos de diálogo que se dan entre individuos vinculados a organizaciones sociales, investigadores, artistas y demás personas que hacen parte de este espacio, que a su vez es casa de la memoria. 
Una vez esbozado y puesto en práctica el proyecto de organización documental, el gran reto es darle vida y activarlo como un instrumento digital que busca ser referente de consulta especializada, y que mediante la vinculación con organismos responsables en la preservación y visibilización de la memoria espera que las generaciones futuras puedan acceder a contenidos que les brindarán elementos para comprender parte de lo que sucedió en nuestro país. Un proyecto que intenta darle forma a la memoria de una sociedad, para que, con el apoyo de otros organismos encargados de salvaguardar el patrimonio documental, se promueva una relación de resistencia y persistencia de la memoria de un país marcado por la guerra.

Vale la pena mencionar que dentro de estos retos para la conservación de las memorias se encuentra uno relevante que no concierne directamente a este proyecto, pero que lo determina: dar continuidad a los procesos de memoria que se realizan con las comunidades y al interior del museo, incluidas la organización y preservación de sus colecciones. Continuidad que se ve amenazada por los constantes cambios de dirección y de personal del museo y que atenta contra el deber de memoria que se le debe a una sociedad marcada por la violencia.

\section{Conclusiones}

Este proyecto ha llevado a entender las colecciones del Museo Casa de la Memoria como un legado para comprender nuestras violencias, resaltar las resistencias y transformar nuestra sociedad. Así pues, las colecciones han sido vistas como un nexo entre el Museo y la memoria de la ciudad, como el espacio para la indagación teórica e histórica sobre nuestro pasado reciente y el lugar para reconstruir los imaginarios sobre el lugar que ha ocupado la violencia en nuestra cultura.

Las discusiones, talleres y jornadas de trabajo que acompañaron el proyecto, permitieron comprender mejor las tareas que hace el Museo, y la manera en que se desarrollan, reconociendo los ciclos que sigue cada uno de los procesos y proyectos y, sobre todo, teniendo consciencia del valor de la información que se produce al interior de la institución. Igualmente, al ser un proyecto que da acceso a los procesos que sustentan el hacer del Museo, tiene un fuerte sentido pedagógico, acorde con su misión educativa. La documentación que alberga el repositorio está seleccionada y organizada de tal manera que pueda servir de referente a otros lugares de memoria y museos que están gestándose desde las comunidades y organizaciones. Es una apertura al exterior, a las investigaciones académicas, a los usos de comunidades y, por qué no, a cuestionamientos sobre los modos de hacer y pensar las memorias. Todo este relacionamiento de los públicos con la documentación del Museo servirá para pensar y gestionar el museo del futuro.

En la misma dirección, el desarrollo de una política de colecciones contribuirá no solo a fortalecer la institución, sino también a estrechar lazos y consolidar alianzas con las personas, grupos, comunidades y organizaciones, permitiendo cumplir a cabalidad con la misión de abrir diálogos plurales e incluyentes que inviten a reflexionar de manera crítica no solo sobre las dinámicas de violencia, sino también sobre el hacer de un museo de memorias. El haber generado un espacio para revisar lo hecho, reflexionar sobre los distintos proyectos y entender las maneras de hacer de la sociedad, ayudará al Museo a cumplir el deber de memoria que da forma a su quehacer, evitando la construcción de una narrativa oficial sobre la violencia a través de la regulación del recuerdo y la institucionalización de la memoria. 
En este sentido, es necesario resaltar que las colecciones, al recoger testimonios esenciales para comprender las dinámicas e impactos que han dejado el conflicto armado y las violencias asociadas en nuestra sociedad, y al resaltar las acciones de resistencia y resiliencia de las personas, organizaciones y comunidades frente a estas, genera unas obligaciones especiales para su administración, que deben trascender la gestión de la información para generar una apropiación social de las memorias de las violencias y las resistencias en nuestra ciudad, departamento y país. Como lo señala claramente el ICOM (2017):

[...] la política de colecciones de un museo debe indicar claramente la importancia de estas en su calidad de testimonios primordiales. Asimismo, se debe velar por que no sean solamente las tendencias intelectuales del momento o las costumbres actuales del museo las que dicten esa importancia. (p. 19).

Esta política servirá como base para definir el lugar que ocupa el Museo en nuestra sociedad en tanto productor de sentidos y significados sobre ese pasado de violencia; sentidos que además se encuentran en tensión permanente con los significados, interpretaciones y demandas de una sociedad que cada día se pregunta más sobre su pasado reciente.

\section{Referencias}

CONSEJO de Medellín (26 de abril, 2015). Acuerdo 005 por medio del cual se crea el establecimiento público Museo Casa de la Memoria. [Gaceta Oficial]. Medellín, 2015.

FUENTES, J. J. Evaluación de bibliotecas y centros de documentación e información. Barcelona: Ediciones Trea, 1999.

HALBWACHS, M. A memória coletiva. São Paulo: Centauro, 2006.

HUYSSEN, A. En busca del futuro perdido. Cultura y memoria en tiempos de globalización. México: Fondo de Cultura Económica, 2002.

ICOM. Código de deontología del ICOM para los Museos, 2017. Recuperado de https://icom.museum/wp-content/uploads/2018/07/ICOM-codigo-Es-web-1.pdf

POLLAK, M. Memoria, olvido y silencio. La producción social de identidades frente a situaciones límite. La Plata: Ediciones el Margen, 2006.

RAMA, Á. La ciudad letrada, Arca, Montevideo, 1984.

TAYLOR, D. El archivo y el repertorio. La memoria cultural y performática en las Américas. Santiago de Chile: Ediciones Universidad Alberto Hurtado, 2016.

TODOROV, T. Los abusos de la memoria. Memoria y ciudad. Medellín: Corporación Región, 1997.

Recebido em: 11/06/2020

Aceito em: 27/06/2020 